\title{
Pricing of HPV Vaccines in Europe: Back to the Future?
}

\author{
Livio Garattini ${ }^{1} \cdot$ Anna Padula $^{1}$
}

Published online: 23 February 2018

(C) Springer International Publishing AG, part of Springer Nature 2018

\section{HPV Background}

Human papilloma viruses (HPV) can cause sexually transmitted infections, which in some cases persist and progress to cancer. Among the 201 HPV genotypes so far identified, more than 40 have been classified as high- and low-risk types according to their risk of progression to cancer [1].

Cervical cancer (CC) is the second most common cancer in women worldwide (about 55,000 new cases every year in Europe), and almost $100 \%$ of these are caused by HPV infection [2], which is also associated with other much less frequent cancers such as anal (around $90 \%$ of cases related to HPV in Europe), vulvar (15\%), vaginal $(70 \%)$, and penile $(30-40 \%)$ cancers. Finally, HPV infection causes benign lesions such as genital warts (GWs) and recurrent respiratory papillomatosis (RRPs).

\section{HPV Vaccination}

HPV vaccination, the first available against a cancer, is now well established in most European countries [3]. Originally reimbursed only for girls in Europe, it has since been extended to boys in a few countries such as Austria and Italy. Besides protecting boys from anal cancers and lesions, male extension potentially implies 'herd immunity' for unvaccinated subjects once a high coverage rate has

Livio Garattini

livio.garattini@marionegri.it

1 CESAV, Centre for Health Economics, IRCCS Institute for Pharmacological Research "Mario Negri”, 24020 Ranica, Italy been achieved, as with any universal vaccination [4]. However, according to the World Health Organization, the priority of HPV immunization should still remain CC prevention through the immunization of only girls before they become sexually active [5].

The bivalent and quadrivalent vaccines have been marketed since 2007 in Europe [6]. Both protect against types 16 and 18 , those most frequently associated with CC (around $70 \%$ of cases) and also provide some level of cross-protection against high-risk types 31, 33 and 45 [5], with recent evidence particularly for the bivalent vaccine $[7,8]$. The quadrivalent vaccine further protects against types 6 and 11, which are responsible for around $90 \%$ of benign GWs and RRPs. Initially administered on a threedose schedule, since 2014 both vaccines have now been reduced to two doses for adolescents [9].

The European Medicines Agency (EMA) approved the nonavalent vaccine in 2015 [2]; this includes five further high-risk oncogenic genotypes (31, 33, 45, 52, and 58) over the quadrivalent vaccine. The main advance offered by the new vaccine should be to raise the protection against CC from around 70 to $90 \%$ of cases.

\section{HPV Vaccine Prices}

The first HPV vaccines were by far the most expensive of all available vaccines at the time of their launch [6], with ex-factory prices around $€ 100$ per dose in most European countries. Since these unusually high prices might have been a major hurdle for vaccination programmes, many health authorities in Western European countries opted for competitive tenders including both vaccines. To account for the difference between the two vaccines in the preventions of GWs, a 'quality score' in favour of the 
quadrivalent vaccine is often added in tender clauses [9] so as not to consider only the best price offered.

The real HPV vaccine prices have fallen steeply over the last few years in many European countries, thanks to competitive tendering. For instance, the price per dose in Italy dropped under $€ 30$ in recent regional tenders [10] and even sunk under $€ 20$ in the Netherlands [11]; experts commonly felt there were similar drops in national tenders in Sweden and the UK (both countries where awarded prices are kept confidential) [12].

This experience showed that prices can drop steeply even when competition is minimal, i.e. only two manufacturers, if vaccines are judged basically equivalent by health authorities for their main health target, i.e. CC prevention in the case of HPV vaccination.

\section{Policy Implications}

The nonavalent vaccine is the element of novelty in HPV vaccination, and its main clinical advantage should be to increase CC prevention from around 70 to $90 \%$. This new vaccine might also dramatically modify the 'market arena' of HPV vaccines. Being marketed by the same manufacturer as the quadrivalent vaccine, its launch was presumably planned to 'cannibalize' the latter, which is perfectly understandable from a research-oriented industry expecting high returns on investments [13]. However, particularly in this period of economic difficulties and limited public expenditure, health authorities must strive to fully exploit their purchasing power on behalf of citizens, as they have done successfully so far for HPV vaccination in many European countries.

On the basis of the existing clinical evidence $[5,7,8]$, it might be hard to consider the nonavalent vaccine a true 'breakthrough' innovation. Rather, the new HPV vaccine might be considered an incremental innovation compared with the two already existing vaccines, which induce some cross-protection on three of the five extra genotypes included in the nonavalent version.

Having agreed on this preliminary assessment, we strongly recommend that health authorities rule out economic modelling as a decision support tool for pricing in the field of HPV vaccination. In fact, most of the published models have already been seen to be mere exercises in long-term forecasting [9], speculating on uncertain longterm 'trade-offs' to boost the chances of showing favourable results for vaccination [14-16]. Particularly when industry sponsored, these models may be considered exercises in marketing rather than science, mainly aimed at supporting prices held high on the basis of various heterogeneous assumptions and estimates open to the authors' discretion and manufacturers' influence [14]; these 'patchwork' analyses are eventually misleading and of scant utility for public policy purposes. The three European economic models focussed on the nonavalent vaccine to support universal coverage that we found in the literature ${ }^{1}$ [17-19] are no exception and seem more like a further (unnecessary) confirmation of this (mal)practice. All sponsored and co-authored by at least two employees of the manufacturer, the three studies exploited the same American model and concluded that the nonavalent vaccine is cost effective at prices largely over $€ 100$ per dose in Austria, Germany and Italy, ignoring in their analyses the much lower prices awarded in domestic tenders for the two other HPV vaccines.

A sensible recommendation for European health authorities is to keep on tendering. Of course, the new tenders must be adapted to the present market situation, so a higher 'quality score' should be attributed to the nonavalent vaccine than to the quadrivalent, but real price competition is to be expected only with the bivalent vaccine because the quadrivalent and nonavalent vaccines are marketed by the same manufacturer. An alternative strategy might be to prioritize the broader protection given by the nonavalent vaccine for HPV prevention and thus try to negotiate with its manufacturer a competitive price inspired by a 'reference-based pricing' approach [20]. For instance, assuming $\mathrm{CC}$ prevention as the major target, a tentative price for the nonavalent vaccine in Italy could be roughly estimated at under $€ 40$ per dose through an easy calculation, ${ }^{2}$ much less than the $€ 63$ price per dose currently offered by the manufacturer [21] and already accepted by most Italian regions. This seems too high in light of not only the negative trend of the real HPV vaccine prices but also of the indications included in the new national vaccine plan [22], which recommends male extension for adolescents (i.e. universal coverage) to all 20 Italian regions. Roughly, this would double HPV vaccination expenditure, a substantial financial increase hardly balanced by an equal health benefit.

\footnotetext{
${ }^{1}$ We searched the PubMed international database to select economic evaluations conducted in EU countries where the HPV nonavalent vaccine is considered for universal vaccination campaigns. We used "papillomavirus vaccine" and "HPV vaccine" and "costs and cost analysis" as search terms. From the 149 articles published in English and initially identified from January 2015 until December 2017, 145 were discarded as studies conducted outside Europe and/or focused on HPV bivalent or quadrivalent vaccines (78); reviews (29); clinical and biological studies (25); or editorials, letters and surveys (13). We finally identified four articles conducted on the nonavalent vaccine in Europe and further excluded one study not considering the male extension of HPV vaccination.

${ }^{2}$ Since the expected increase of CC prevention thanks to the nonavalent vaccine is $20 \%$, and the awarded prices in the last regional tenders went under $€ 30$ per dose, a reasonable price could be $€ 38$ per dose $(€ 29 \times 0.9 / 0.7)$.
} 


\section{Comment}

Vaccination is often perceived as a cost-effective health intervention. However, in this apparently never-ending period of economic difficulties and limited public expenditure, the sky-high prices of new vaccines are a major concern in Western European countries. Although it is the purview of public health experts to advise decision makers on what new vaccinations to adopt and whether to do so, health economists should provide information on the potential choices of public health sustainable in practice by promoting strategies to enhance competitive prices whenever possible. To guarantee the economic sustainability of vaccinations for society in the long run, this might imply not always maximizing individual protection with the newest vaccine in the short term. Since any 'competitor' is (obviously) expected to be against price competition [13], striving more to stress any 'plus' of its product, the main issue is where to 'draw the line' of substantial equivalence between similar products.

To cope with this issue for HPV vaccines, here we offer tentative proposals open to debate.

\section{Compliance with Ethical Standards}

Funding No sources of funding were used to conduct this study or prepare this manuscript.

Conflict of interest Anna Padula and Livio Garattini have no conflicts of interest that are directly relevant to the content of this article.

\section{References}

1. International Human Papillomavirus Reference Center: Karolinska Institutet, 2015. http://www.hpvcenter.se/html/refclones.html. Accessed 27 Dec 2017.

2. Assessment report Gardasil 9 International non-proprietary name: human papillomavirus 9-valent vaccine (recombinant, adsorbed). European Medicine Agency, Committee for medicinal products for human use. 2015. http://www.ema.europa.eu/docs/en_GB/ document_library/EPAR_-_Public_assessment_report/human/ 003852/WC500189113.pdf Accessed 28 Dec 2017.

3. Bruni L, Diaz M, Barrionuevo-Rosas L, Herrero R, Bray F, Bosch FX, et al. Global estimates of human papillomavirus vaccination coverage by region and income level: a pooled analysis. Lancet Glob Health. 2016;4:e453-63.

4. Garattini L, van de Vooren K. HPV vaccination for boys? Talking economic sense. J Sex Med. 2012;9(8):2195-6.

5. World Health Organization. Schedules and strategies for HPV immunization-background paper for Strategic Advisory Group of Experts (SAGE) deliberations. 2016. http://www.who.int/
immunization/sage/meetings/2016/october/1_HPV_vaccine_ background_document_27Sept2016.pdf?ua=1. Accessed 3 Jan 2018.

6. Garattini L, van de Vooren K, Curto A. Pricing human papillomavirus vaccines: lessons from Italy. Pharmacoeconomics. 2012;30:213-7.

7. Bissett SL, Godi A, Jit M, Beddows S. Seropositivity to nonvaccine incorporated genotypes induced by the bivalent and quadrivalent HPV vaccines: a systematic review and meta-analysis. Vaccine. 2017;35(32):3922-9.

8. Brotherton JML. Confirming cross-protection of bivalent HPV vaccine. Lancet Infect Dis. 2017;17(12):1227-8.

9. Garattini L, Curto A, van de Vooren K. Long-term modeling on HPV vaccination: do we really need any more? Expert Rev Pharmacoecon Outcomes Res. 2015;15(2):191-4.

10. Garattini L, Curto A, Freemantle N. Vaccination planning in Italy: increasing vaccines while reducing coverage? Expert Rev Pharmacoecon Outcomes Res. 2016;16(5):547-8.

11. Qendri V, Bogaards JA, Berkhof J. Health and economic impact of a tender-based, sex-neutral human papillomavirus 16/18 vaccination program in the Netherlands. J Infect Dis. 2017;216(2):210-9.

12. Garattini L, Van de Vooren K, Freemantle N. Tendering and value-based pricing: lessons from Italy on human papilloma virus vaccines. J R Soc Med. 2014;107(1):4-5.

13. Garattini L, Padula A. Competition in pharmaceuticals: more product- than price-oriented? Eur J Health Econ. 2018;19(1):1-4.

14. Koleva D, De Compadri P, Padula A, Garattini L. Economic evaluation of human papilloma virus vaccination in the European Union: a critical review. Intern Emerg Med. 2011;6:163-74.

15. Newal AT, Beutels P, Wood JG, Edmunds WJ, MacIntyre CR. Cost effectiveness analyses of human papillomavirus vaccination. Lancet Infect Dis. 2007;7:289-96.

16. Puig-Junoy J, Lopez-Valcarcel BG. Economic evaluations of massive HPV vaccination: within study and between study variations in incremental cost per QALY gained. Prev Med. 2009;48:444-8.

17. Boiron L, Joura E, Largeron N, Prager B, Uhart M. Estimating the cost-effectiveness profile of a universal vaccination programme with a nine-valent HPV vaccine in Austria. BMC Infect Dis. 2016;16:153.

18. Largeron N, Petry KU, Jacob J, Bianic F, Anger D, Uhart M. An estimate of the public health impact and cost-effectiveness of universal vaccination with a 9-valent HPV vaccine in Germany. Expert Rev Pharmacoecon Outcomes Res. 2017;17(1):85-98.

19. Mennini FS, Bonanni P, Bianic F, de Waure C, Baio G, Plazzotta G, Uhart M, Rinaldi A, Largeron N. Cost-effectiveness analysis of the nine-valent HPV vaccine in Italy. Cost Eff Resour Alloc. 2017;15:11. https://doi.org/10.1186/s12962-017-0073-8.

20. Garattini L, Curto A, Freemantle N. Pharmaceutical price schemes in Europe: time for a 'Continental' one? Pharmacoeconomics. 2016;34(5):423-6.

21. Azienda Sanitaria Locale della Provincia di Foggia. 2017. https:// www.sanita.puglia.it/.../Delibera/76783f4d-59b0-4b36-96944069309479ac. Accessed 27 Dec 2017.

22. Ministero della Salute. Piano Nazionale Prevenzione Vaccinale 2017-2019. 18 February 2017. Gazzetta Ufficiale della Repubblicata Italiana, Rome. 